\title{
Nurse-conducted smoking cessation with minimal inter-vention in a lung clinic: a randomized controlled study
}

\author{
P. Tønnesen, K. Mikkelsen, C. Markholst, A. Ibsen, M. Bendixen, \\ L. Pedersen, R. Fuursted, L.H. Hansen, H. Stensgaard, R. Schiøtz, \\ T. Petersen, L. Breman, P. Clementsen, T. Evald
}

Nurse-conducted smoking cessation with minimal intervention in a lung clinic: a randomized controlled study. P. Tonnesen, K. Mikkelsen, C. Markholst, A. Ibsen, M. Bendixen, L. Pedersen, R. Fuursted, L.H. Hansen, H. Stensgaard, R. Schiфtz, T. Petersen, L. Breman, P. Clementsen, T. Evald. @ ERS Journals Ltd 1996.

ABSTRACT: This study aimed to evaluate the effect of a motivational, minimal intervention approach to smoking cessation in an open, randomized design conducted by nurses as routine work in a lung clinic.

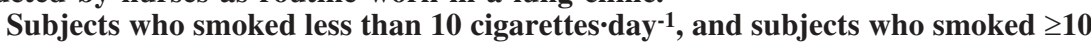
cigarettes day $^{-1}$ and who had refused to participate in a smoking cessation trial with nicotine replacement therapy, were randomly allocated to a motivational approach to smoking cessation or to a control group. The motivational approach consisted of a nurse-conducted 5 min consultation concerning reasons to quit smoking, brochures about smoking cessation and advice about how to quit. After 4-6 weeks, subjects in the motivational group received a letter encouraging them to quit smoking. After 1 year, all subjects were contacted by phone and smoking status reported. Subjects claiming to be abstinent attended the clinic for carbon monoxide verification.

A total of 507 subjects were enrolled, 254 in the motivational group and 253 in the control group. The mean age of the motivational group was 51 yrs, $50 \%$ were males and they smoked a mean of 13 cigarettes day $^{-1}$. The mean age of the control group was $53 \mathrm{yrs}, \mathbf{6 1 \%}$ were males and they smoked a mean of 12 cigarettes-day ${ }^{-1}$. At the 1 year follow-up, the success rate for point prevalence (no smoking at 1 year and during the preceding month) was $8,7 \%$ in the motivational group versus $3.6 \%$ in the control group $(\mathrm{p}=\mathbf{0 . 0 2 5})$. The 12 months sustained success rate (no smoking at all during the year) was 3.1 versus $1.2 \%(p=0.22)$. The point prevalence for light smokers $\left(<10\right.$ cigarettes $^{\cdot}$ day $\left.^{-1}\right)$ was $13.9 \%$ in the motivational group versus $6.3 \%$ in control group $(\mathrm{p}=\mathbf{0 . 1 2})$, and for heavy smokers $(10$ or more cigarettes day $\left.^{-1}\right) 5.2 \%$ versus $1.9 \%(\mathrm{p}=0.20)$.

In conclusion, the effect of this nurse-conducted, minimal intervention, motivational approach seems promising as the quit rate at 1 year follow-up had doubled. Eur Respir J., 1996, 9, 2351-2355.
Dept of Pulmonary Medicine, Gentofte Hospital, 2900 Hellerup, Copenhagen, Denmark.

Correspondence: P. Tønnesen

Pulmonary Department Y

KAS Gentofte Amtssygehus

Niels Andersensvej

2900 Hellerup

Denmark

\section{Keywords: Lung clinic}

minimal intervention

motivation

nurse

smoking cessation

Supported by a grant from Pharmacia, Nicorette, Sweden and The Danish Society for Pulmonary Diseases (Nationalforeningen).

Received: February 121996

Accepted after revision July 171996
Smoking is an important risk factor for several potential preventable diseases $[1,2]$. As almost $85 \%$ of chronic obstructive pulmonary disease (COPD) and lung cancer cases are induced by smoking [3], it seems to be a relevant task to tackle smoking cessation in lung clinics. Moreover, the therapy available for these diseases at present has produced disappointing results.

During the last $10 \mathrm{yrs}$, nicotine replacement therapy has been extensively evaluated and a doubling of the success rate is to be expected [4-6]. However, most trials have included only subjects consuming more than 10-15 cigarettes, and in low-dependent smokers nicotine replacement has shown little or no effect on cessation success rate $[7,8]$.

As early as 1969, an uncontrolled study with "routine" advice against smoking in a chest clinic comprising 187 smokers was published [9]. However only a few trials of smoking cessation have been reported from lung clinics and the results have been conflicting [10-12].

Several low intervention studies of smoking cessation have reported a 1 year success rate below 5\% [13-16]. The British Thoracic Society has conducted a large multicentre smoking cessation study with minimal intervention in hospitals and chest clinics with 2,854 smokers suffering from smoking-related diseases [17]. A significant increase in the 12 month success rate was found between "usual intervention" and physicians advice to stop smoking combined with follow-up letters, i.e. 5.2 versus $8.5 \%$. Thus, as the resources in most hospitals are limited at the present time, a low intervention approach as above was chosen.

The aim of this study was to evaluate whether a nurseconducted minimal intervention programme in a lung clinic had any effect on smoking cessation after 1 year, 
in a group of light smokers consuming less than 10 cigarettes $\cdot$ day $^{-1}$ and in a group of smokers of $\geq 10$ cigarettes. day $^{-1}$. Smokers from the latter group had previously declined to participate in a nicotine replacement smoking cessation study.

\section{Material}

\section{Design}

This was an open, randomized study. The patients were mostly referred from their general practitioner for chest radiography and/or lung function testing. A poster in the waiting room proclaimed that a trial was ongoing and that smoking habits would be recorded. The inclusion period was 24 weeks.

The nurses completed the smoking records on all consecutive patients, and subjects smoking $<10$ cigarettes $\cdot$ day $^{-1}$ were invited to participate in a smoking cessation trial. After informed consent, the subjects were randomized to a motivational approach or a control group.

Subjects smoking $\geq 10$ cigarettes $\cdot$ day $^{-1}$ were invited to participate in a smoking cessation trial with nicotine replacement [18], but if not interested they were invited to participate in the motivational study. Exclusion criteria were: age outside 20-70 yrs, subjects suspected of having lung cancer, senile subjects, and nonco-operative subjects.

Subjects in the motivational group received a letter, 4-6 weeks after the initial visit, encouraging them to stop smoking.

After 1 year, a nurse contacted all subjects by phone (up to three times), and subjects claiming to be nonsmokers were seen in the clinic for carbon monoxide verification and recording of body weight. Subjects were considered lost to follow-up after three fruitless telephone calls on separate days, and were then counted as smokers. In the telephone interview, the subjects actual smoking habits were recorded, as well as nicotine dependence using the Fagerström Tolerance Questionnaire $(0-11)$; motivation to quit $(0-5)$; stress intensity (0-3); stress frequency $(0-3)$; satisfaction with life during the preceding year $(0-2)$.

The 1 year sustained success rate was defined as subjects who stopped smoking at the time of the initial intervention and did not smoke at all during that year as confirmed by carbon monoxide analysis at followup. The 1 year point prevalence success rate was defined as subjects not smoking at follow-up or during the preceding month as confirmed by carbon monoxide analysis.

\section{Assessments}

Carbon monoxide in end-expiratory air after a $15 \mathrm{~s}$ breathholding was measured at entry and at the 1 year follow-up using a carbon monoxide analyser (Bedfont Monitor, Bedfont Technical Instruments, Sittingbourne, UK). Carbon monoxide levels of less than 10 parts per million (ppm) $\left(420 \mathrm{nmol} \cdot \mathrm{L}^{-1}\right)$ were compatible with classification as a nonsmoker [19]. Subjects were weighed on the same scale at entry and after 1 year.
The self-completed paper-and-pencil Fagerström Tolerance Questionnaire (FTQ) was used to measure each subjects degree of dependence on nicotine, with a possible sum of 0-11 [20]. Also, one question from the Fagerström Tolerance Nicotine Dependence (FTND) questionnaire [21] was completed: How soon after you wake do you smoke your first cigarette? 0-5 min: 3 points; 6-30 min: 2 points; $31-60 \mathrm{~min}$ : 1 point; after 60 min: 0 points. The daily consumption of tobacco was recorded (cigarettes, cigars $=5$ cigarettes; cheroots $=2$ cigarettes; pipe $(1 \mathrm{~g})=1$ cigarette). The motivation to quit smoking was scored on a six-point scale: $0=$ not at all; 1=little; 2=some; $3=$ moderate; $4=$ much; 5=very much.

\section{Nurse education}

All nurses working in the lung clinic participated in the study without provision of extra resources. They followed a course of four $2 \mathrm{~h}$ lessons concerning smoking cessation and containing the general rules of smoking cessation, nicotine replacement therapy, carbon monoxide measurement, completion of the Fagerström scale, review of the protocol and training of the motivational approach. During the study, three meetings were held to discuss and solve problems and to try to enhance the nurses motivation.

\section{Motivational group}

The nurse recorded the smoking habits, measured the carbon monoxide level, and received the completed Fagerström questionnaire. She then motivated the subject to stop smoking during a 5 min conversation. She told the subject why he/she should stop smoking (decreased lung function, COPD, hypertension, myocardial infarction etc.) and the risk from continuing to smoke in general. She showed a figure with the decline of lung function over time in smokers versus nonsmokers, and the subject received two brochures about the health hazards of smoking and advice about how to quit. The nurse also informed the subject about the basic rules of smoking cessation and that nicotine patches or chewing gum might help, and were available over-the-counter from pharmacies.

After 4-6 weeks, the subjects received a letter asking if they had already stopped smoking and, if not, encouraging them to do so.

\section{Control group}

The smoking habits of the control group were recorded, they completed the Fagerström scale and carbon monoxide level was measured. They were then told that they would be contacted in 1 year to be asked about their smoking habits. No advice to stop smoking was given.

\section{Ethics}

The study was conducted in accordance with the Declaration of Helsinki, and was approved by the local Ethics Committee. 


\section{Statistical analysis}

Mean and SD were calculated for most parameters. Nonparametric tests (Chi-squared test) were used for comparisons. All p-values were two-tailed, and a p-value equal to or less than 0.05 was considered to be a significant difference. A logistic regression analysis predicting 1 year outcome from treatment, by age, sex, carbon monoxide level, Fagerström score, number of cigarettes, and nicotine content per cigarette, was performed.

\section{Results}

A total of 2,140 subjects attended the lung clinic in the study period, of whom 1,101 (51\%) (610 females and 491 males) were nonsmokers. Of the smokers: 86 (4\%) were not interested in participating at all (43 females and 43 males); 446 (21\%) (smokers of $>9$ cigarettes $\cdot$ day $^{-1}$ ) were enrolled in the parallel nicotine therapy trial; and $507(24 \%)$ were enrolled in the present study. Of enrolled subjects, 197 smoked $<10$ cigarettes $\cdot$ day $^{-1}$ and 310 smoked $\geq 10$ cigarettes $\cdot$ day $^{-1}$. These subjects were allocated to the motivational arm $(n=254)$ or the control arm $(n=253)$. The demographic data are presented in table 1.

Sixty two subjects (12\%) were lost to follow-up and counted as smokers. The 1 year success rate (point prevalence) verified with carbon monoxide level $<10 \mathrm{ppm}$ was $8.7 \%$ in the motivational group and $3.6 \%$ in the control group $(\mathrm{p}=0.025)$. The 1 year self-reported sustained success rate was 3.1 versus $1.2 \%(\mathrm{p}=0.22)$.

For subjects smoking $<10$ cigarettes $\cdot$ day $^{-1}$ the success rate in the motivational group was 13.9 versus $6.3 \%$ in

Table 1. - Demographic data at entry $(n=507)$

\begin{tabular}{|c|c|c|c|c|}
\hline & \multicolumn{2}{|c|}{ 1-9 cigarettes $\cdot$ day $^{-1}$} & \multicolumn{2}{|c|}{$\geq 10$ cigarettes $\cdot$ day $^{-1}$} \\
\hline & Motivation & Control & Motivation & Control \\
\hline $\operatorname{Sex} \quad M / F$ & $49 / 52$ & $51 / 45$ & $79 / 74$ & $104 / 53$ \\
\hline Age yrs & $\begin{array}{c}53 \\
(23-70)\end{array}$ & $\begin{array}{c}56 \\
(21-70)\end{array}$ & $\begin{array}{c}50 \\
(21-70)\end{array}$ & $\begin{array}{c}51 \\
(20-70)\end{array}$ \\
\hline Weight $\mathrm{kg}$ & $\begin{array}{c}68.9 \\
(35-105)\end{array}$ & $\begin{array}{c}69.8 \\
(47-94)\end{array}$ & $\begin{array}{c}73.4^{\#} \\
(42-150)\end{array}$ & $\begin{array}{c}68.5 \\
(42-105)\end{array}$ \\
\hline Cig $\cdot$ day $^{-1} n$ & $\begin{array}{c}4.1 \\
(1-9)\end{array}$ & $\begin{array}{c}3.8 \\
(1-9)\end{array}$ & $\begin{array}{c}18.7 \\
(10-60)\end{array}$ & $\begin{array}{c}17.4 \\
(10-50)\end{array}$ \\
\hline $\mathrm{Nic} \cdot \mathrm{cig}^{-1} \mathrm{mg}$ & $\begin{array}{c}1.1 \\
(0.8-1.5)\end{array}$ & $\begin{array}{c}1.1 \\
(0.6-1.5)\end{array}$ & $\begin{array}{c}1.1 \\
(0.7-1.5)\end{array}$ & $\begin{array}{c}1.2 \\
(0.7-1.5)\end{array}$ \\
\hline FTQ & $\begin{array}{c}3.1 \\
(0-11)\end{array}$ & $\begin{array}{c}3.0 \\
(1-6)\end{array}$ & $\begin{array}{c}5.5 \\
(1-10)\end{array}$ & $\begin{array}{c}5.5 \\
(1-10)\end{array}$ \\
\hline $\begin{array}{l}\text { First cig* } \\
\text { (FTND) }\end{array}$ & $\begin{array}{c}0.7 \\
(0-3)\end{array}$ & $\begin{array}{c}0.6 \\
(0-3)\end{array}$ & $\begin{array}{c}1.5 \\
(0-3)\end{array}$ & $\begin{array}{c}1.6 \\
(0-3)\end{array}$ \\
\hline $\mathrm{CO}$ expired ppm & $\begin{array}{c}11 \\
(1-38)\end{array}$ & $\begin{array}{c}12 \\
(1-38)\end{array}$ & $\begin{array}{c}18 \\
(1-39)\end{array}$ & $\begin{array}{c}19 \\
(2-46)\end{array}$ \\
\hline $\begin{array}{l}\text { Motivation } \\
\text { to quit }\end{array}$ & $\begin{array}{c}2.1 \\
(0-5)\end{array}$ & $\begin{array}{c}1.9 \\
(0-5)\end{array}$ & $\begin{array}{c}1.7 \\
(0-5)\end{array}$ & $\begin{array}{c}2.0 \\
(0-5)\end{array}$ \\
\hline
\end{tabular}

Values are presented as mean, and range in parenthesis. *: How soon after you wake do you smoke your first cigarette? 0-5 min: 3 points; $6-30$ min: 2 points; $31-60$ min: 1 point; after 60 min: 0 points. M: male; F: female; Cig: cigarettes; Nic: nicotine; FTQ: Fagerström Tolerance Questionnaire; FTND: Fagerström Tolerance Nicotine Dependence. \#: $\mathrm{p}=0.01$, versus Controls $\geq 10 \mathrm{cig} \cdot \mathrm{day}^{-1}$.
Table 2. - Allocation of smokers, 1 year point success rate and sustained success rate (SSR)

\begin{tabular}{ccccccc}
\hline & \multicolumn{2}{c}{$\begin{array}{c}c \text { cig } \cdot \text { day }^{-1} \\
\mathrm{n}=197\end{array}$} & & \multicolumn{2}{c}{$\begin{array}{c}\geq 10 \mathrm{cig} \cdot \text { day }^{-1} \\
\mathrm{n}=310\end{array}$} \\
\cline { 2 - 3 } \cline { 6 - 7 } & $\begin{array}{c}\text { Motivation } \\
\mathrm{n}=101\end{array}$ & $\begin{array}{c}\text { Control } \\
\mathrm{n}=96\end{array}$ & & $\begin{array}{c}\text { Motivation } \\
\mathrm{n}=153\end{array}$ & $\begin{array}{c}\text { Control } \\
\mathrm{n}=157\end{array}$ \\
\hline PSR \% & 13.9 & 6.3 & & 5.2 & 1.9 \\
SSR \% & 5.9 & 3.1 & & 1.3 & 0.0 \\
\hline
\end{tabular}

Total smokers: $n=507$. Cig: cigarettes; PSR: point success rate, defined as subjects not smoking at follow-up or during the preceding month, as confirmed by $\mathrm{CO}$ analysis; SSR: sustained success rate, defined as subjects who stopped smoking at the time of the initial intervention and did not smoke at all during the year, as confirmed by $\mathrm{CO}$ analysis.

the control group ( $\mathrm{p}=0.12$ ), and in subjects $\geq 10$ cigarettes $\cdot$ day $^{-1}$ the success rate was 5.2 versus $1.9 \%(\mathrm{p}=0.20)$ (table 2). Comparing the success rate for the motivational group separately, the success was higher in light smokers $\left(<10\right.$ cigarettes $\cdot$ day $\left.^{-1}\right) \quad 13.9 \%$ compared with heavier smokers $\left(\geq 10\right.$ cigarettes $^{2}$ day $\left.^{-1}\right) 5.2 \%(p=0.03)$, odds ratio (OR) 2.7. The self-reported mean (SD) abstinence period was 9.4 (31) days in the motivational group and 11.6 (40) days in controls.

At follow-up, the median carbon monoxide level was $2 \mathrm{ppm}$ in the 31 success subjects (values: $1 \mathrm{ppm}(\mathrm{n}=8)$, $2 \mathrm{ppm}(\mathrm{n}=11), 3 \mathrm{ppm}(\mathrm{n}=11)$, and $4 \mathrm{ppm}(\mathrm{n}=1))$. Cigarette consumption was almost unchanged at the 1 year follow-up in failures, with a mean change in the number of daily cigarettes of -0.13 and 0.03 in the motivational group and controls, respectively; and change in total daily tobacco intake from 14.67 to $14.48 \mathrm{~g}$ and 14.12 to $14.05 \mathrm{~g}$, respectively. For nicotine content per cigarette, Fagerström score, and "time to first cigarette in the morning" no change was observed between entry and the 1 year follow-up values. The mean (SD) motivation to quit smoking decreased in controls (-0.41 (2.0)) and in the motivational group (-0.10 (1.9)).

In all failures $(n=414)$, a small increase in FTQ was found of 0.3 (95\% CI $0.2-0.5)$, and a decrease in the motivation to quit of $-0.3(95 \%$ CI $-0.5--0.1)$, but no significant changes for the other parameters. Amongst the failures, $4.6 \%$ reported having used nicotine gum and $5.4 \%$ nicotine patch, compared with 6.7 and $13.3 \%$ in the successful patients. These subjects had bought nicotine products over-the-counter in the pharmacies after having read the brochures at entry. The body weight in abstinent subjects increased from 72.4 (43-110) $\mathrm{kg}$ at entry to $77.8(52-111) \mathrm{kg}$ after 1 year $(\mathrm{p}<0.000)(\mathrm{n}=$ 28).

A logistic regression analysis with 1 year success against several other parameters showed that the active treatment (motivation), the first question from FTND i.e. "time to first cigarette", and entry carbon monoxide level were significant predictors of success, although the $\mathrm{r}^{2}$-values were low (0.15-0.20). In all analyses, sex and age was of no importance. There was a trend towards lower values for most variables (age, cigarettes $\cdot$ day $^{-1}$, FTQ, CO levels) at entry in successful patients compared with failures (table 3 ). 
Table 3. - Demographic data at entry for failures in the motivational group and controls and for 1 year point success patients excluding patients lost to follow-up $(n=445)$

\begin{tabular}{lccc}
\hline & Motivation & Control & Success \\
\hline Sex M/F & $104 / 96$ & $132 / 82$ & $15 / 16$ \\
Age yrs & 52 & 53 & 48 \\
& $(21-70)$ & $(20-70)$ & $(23-68)$ \\
Weight kg & 70.9 & 69.2 & 72.4 \\
& $(35-150)$ & $(44-105)$ & $(43-110)$ \\
Cig·day-1 n & 13.3 & 12.6 & 8.3 \\
& $(1-60)$ & $(1-50)$ & $(1-25)$ \\
Nic· cig-1 mg & 1.1 & 1.1 & 1.1 \\
& $(0.7-1.5)$ & $(0.7-1.5)$ & $(0.8-1.5)$ \\
FTQ & 4.6 & 4.6 & 3.9 \\
$(0-11)$ & $(0-11)$ & $(0-10)$ & $(1-8)$ \\
First cig* & 1.2 & 1.2 & 0.6 \\
(FTND) & $(0-3)$ & $(0-3)$ & $(0-2)$ \\
CO expired ppm & 15 & 16 & 11 \\
& $(1-38)$ & $(2-61)$ & $(3-26)$ \\
Motivation & 1.9 & 1.9 & 2.1 \\
to quit & $(0-5)$ & $(0-5)$ & $(0-5)$ \\
\hline
\end{tabular}

Values are presented as mean, and range in parenthesis. *: How soon after you wake do you smoke your first cigarette? 0-5 min: 3 points; $6-30$ min: 2 points; $31-60$ min: 1 point; after 60 min: 0 points. For definitions see legend to table 1 .

\section{Discussion}

The effect of this nurse-conducted, brief, minimal smoking intervention in a chest clinic doubled the quit rate after 1 year; however, this was only statistically significant when calculated as point prevalence, which was defined as not smoking at 1 year follow-up and during the preceding month.

These data need to be interpreted with some caution as carbon monoxide level was only measured once. On the other hand, more intensive follow-ups might have biased the minimal intervention design itself.

In a large study by general practitioners with minimal intervention comprising 5,560 smokers, the 1 year quit rate was 1.9 versus $0.9 \%$ in the control group, which is in the same level as the sustained success rate in the present study [13]. And in a group of 630 self-referred smokers about to quit "on their own", after exclusion of 671 smokers who were suspected as not likely to stop abruptly on their own, the 6 months abstinence rate verified by CO level was $3 \%$, which is in the same low range as the present study and other studies with minimal intervention [13-15, 22]. In the large British Thoracic Society study [17] with a comparable design, the 12 months success rate of $8.5-8.8 \%$ is in the same range as the $8.7 \%$ in the present study.

The success rate was higher in light compared with moderate smokers in the motivation groups, in accordance with other smoking cessation studies where light smokers had a higher success rate compared with moderate-to-heavy smokers without use of nicotine supplementation. Furthermore, in the present study, the heavier smokers would not participate in a study with nicotine replacement therapy, thus their motivation to quit was suspected to be low.

The enrolment of smokers in this study was experienced as a "surprise attack", as no subjects were referred to the lung clinic for smoking cessation. The smokers low motivation to quit in combination with the minimal intervention used for smoking cessation is reflected in the low sustained abstinence rate after 1 year of $3.1 \%$.

Lung clinics seem to be an appropriate place to encourage smoking cessation. The staff are educated in the care of COPD and asthma patients, and many of the behavioural skills used in treatment of this group are useful in smoking cessation. The clientele in lung clinics comprises healthy smoking subjects and COPD patients, which is an appropriate target population, and in the guidelines for treating COPD patients smoking cessation plays an important role [23]. The success rate in patients with respiratory disorders was lower compared with patients with cardiac disorders in the British Thoracic Society study [17], and we found in a chest clinic smoking cessation trial a lower outcome in subjects with very mild chronic bronchitis according to the World Health Organization (WHO) criteria [24]. Among 1,118 coal-miners chronic respiratory symptoms was inversely associated with smoking cessation, while respiratory impairment was positively associated with smoking cessation [25]. This obviously lower quit rate among COPD patient might, in part, be due to selection. As many of the smoking COPD patients might have quit earlier leaving the committed smokers [26].

Another important finding is that in failures the cigarette consumption was unchanged after 1 year, i.e. smoking reduction seems impossible, at least in this group of low motivated subjects. This is in accordance with another study on nicotine patches and more motivated smokers, in which we also found unchanged cigarette consumption after 1 year in failures [27].

Although nurse-conducted smoking cessation appears to attain a success rate similar to physician-conducted therapy [28], all health professionals should work together as a team in this area.

From this study, it is obvious that our nurse-conducted, minimal motivational smoking cessation set-up in a lung clinic should be implemented as routine work in other lung clinics. The cost is minimal, as our model can be implemented without the use of extra "manpower". Several studies have attested to the efficacy of minimal interventions [29]. Advice to quit combined with one or more "standard" follow-up letters, appear to be important elements in such an approach [17].

\section{References}

1. US Surgeon General. The health consequences of smoking: nicotine addiction. US Department of Health and Human Services, Rockville, USA, 1988.

2. US Surgeon General . The health benefits of smoking cessation. US Department of Health and Human Services, Rockville, USA, 1990.

3. Smoking Cessation in 1994. J Smoking Related Dis 1994; 5 (Suppl. 1); 3-328.

4. Tønnesen P, Fagerström KO. Nicotine replacement. In: Richmond R, Ed. Interventions for Smokers. USA, Williams \& Wikins, USA, 1994; pp. 3-28.

5. Tønnesen P. Smoking cessation programs. In: Hansen $\mathrm{HH}$, ed. Lung Cancer. Kluwer Academic Publishers, Boston, 1994; pp. 75-89.

6. Silagy C, Mant D, Fowler G, Lodge M. Meta-analysis on efficacy of nicotine replacement therapies in smoking cessation. Lancet 1994; 343: 139-142.

7. Sutherland G, Stapleton JA, Russell MAH, et al. 
Randomised controlled trial of nasal nicotine spray in smoking cessation. Lancet 1992; 340: 324-329.

8. Benowitz N. Nicotine replacement therapy. What has been accomplished - can we do better? Drugs 1993; 45: 157-170.

9. Williams HO. Routine advice against smoking: a chest clinic pilot study. Practitioner 1969; 202: 672-676.

10. Daughton DN, Fix AJ, Cass I, Patil KD. Smoking cessation among patients with chronic obstructive pulmonary disease (COPD). Addict Behav 1980; 5: 125-128.

11. Hall SM, Bachman J, Henderson JD, Barsdoe R, Jones RT. Smoking cessation in patients with cardiopulmonary disease:an initial study. Addict Behav 1983; 8: 33-42.

12. British Thoracic Society. Comparison of four methods of smoking withdrawal in patients with smoking-related diseases. Br Med J 1983; 286: 595-597.

13. Slama K, Karsenty S, Hirsch A. Effectiveness of minimal intervention by general practitioners with their smoking patients: a randomised, controlled trial in France. Tobacco Control 1995; 4: 162-169.

14. Bronson DL, Flynn BS, Solomon LJ, Vacek P, SeckerWalder RH. Smoking cessation counselling during periodic health examinations. Arch Intern Med 1989; 149: 1653-1656.

15. Russell MAH, Wilson C, Taylor C, Baker CD. Effect of general practitioners advice against smoking. $\mathrm{Br} \mathrm{Med}$ $J$ 1979; 2: 231-235.

16. Glynn TJ. Relative effectiveness of physician-initiated smoking cessation programs. Cancer Bull 1988; 40: 359-364.

17. British Thoracic Society. Smoking cessation in patients: two further studies by the British Thoracic Society. Thorax 1990; 45: 835-840.

18. Tønnesen P, Mikkelsen P, Ewald T, Clemmensen P, Markholst C. Routine smoking cessation with 4 nicotine regimens in a lung clinic (Abstract). Eur Respir $J$ 1995; 8 (Suppl.): 112s.
19. Jarvis MJ, Russell MA, Saloojee Y. Expired air carbon monoxide: a simple breath test of tobacco smoke intake. Br Med J 1980; 281: 484-485.

20. Fagerström KO, Schneider NG. Measuring nicotine dependence: a review of the Fagerström Tolerance Questionnaire. J Behav Med 1989; 12: 159-182.

21. Fagerström KO, Heatherton TF, Kozlowski LT. Nicotine addiction and its assessment. Ear Nose Throat J 1991; 69: 763-768.

22. Wilson DM, Taylor W, Gilbert R, et al. A randomized trial of a family physician intervention for smoking cessation. JAMA 1988; 260: 1570-1574.

23. ATS Statement. Standards for the diagnosis and care of patients with chronic obstructive pulmonary disease. Am J Respir Crit Care Med 1995; 152: S77-S120.

24. Tønnesen P, Fryd V, Hansen M, et al. Two and four $\mathrm{mg}$ nicotine chewing gum and group counselling in smoking cessation:an open randomized trial with a 22 month follow-up. Addict Behav 1988; 13: 17-27.

25. Ames RG, Hall DS. Smoking cessation among coalminers as predicted by baseline respiratory function and symptoms: a 5 year prospective study. Prev Med 1985; 14: 181-185.

26. Daughton DM, Fix JA, Kass I, Patil KD. Smoking cessation among patients with chronic obstructive pulmonary disease (COPD). Addict Behav 1980; 5: 125-128.

27. Nørregaard J, Tønnesen P, Simonsen K, Petersen L, Säwe U. Smoking habits in relapsed subjects from a smoking cessation trial after one year. Br J Addict 1992; 87: 1189-1194.

28. Taylor CB, Houston-Miller N, Killen JD, DeBusk RF. Smoking cessation after acute myocardial infarction: effects of a nurse-managed intervention. Ann Intern Med 1990; 113: 118-123.

29. Fiore MC, Piasecki TM, Baker TB. Signal and noise in minimal interventions for smoking cessation. Tobacco Control 1995; 4: 114-116. 